\title{
The Incidence of Induced Abortion in the Philippines: Current Level and Recent Trends
}

\author{
By Fatima Juarez, \\ Josefina Cabigon, \\ Susheela Singh \\ and Rubina \\ Hussain
}

Fatima Juarez is professor-researcher, Centre for Demographic, Urban and

Environmental Studies, El Colegio de Mexico, Mexico City.

Josefina Cabigon is professor, Population Institute, University of the Philippines, Quezon City. Susheela Singh is vice president and Rubina Hussain is research associate, both with the Guttmacher Institute, New York.

\begin{abstract}
CONTEXT: In the Philippines, abortion is legally restricted. Nevertheless, many women obtain abortions-often in unsafe conditions - to avoid unplanned births. In 1994, the estimated abortion rate was 25 per 1,000 women peryear; no further research on abortion incidence has been conducted in the Philippines.
\end{abstract}

METHODS: Data from 1,658 hospitals were used to estimate abortion incidence in 2000 and to assess trends between 1994 and 2000, nationally and by region. An indirect estimation methodology was used to calculate the total number of women hospitalized for complications of induced abortion in 2000 (averaged data for 1999-2001), the total number of women having abortions and the rate of induced abortion.

RESULTS: In 2000, an estimated 78,900 women were hospitalized for postabortion care, 473,400 women had abortions and the abortion rate was 27 per 1,000 women aged 15-44 per year. The national abortion rate changed little between 1994 and 2000; however, large increases occurred in metropolitan Manila (from 41 to 52) and Visayas (from 11 to 17). The proportions of unplanned births and unintended pregnancies increased substantially in Manila, and the use of traditional contraceptive methods increased in Manila and Visayas.

CONCLUSION: The increase in the level of induced abortion seen in some areas may reflect the difficulties women experience in obtaining modern contraceptives as a result of social and political constraints that affect health care provision. Policies and programs regarding both postabortion care and contraceptive services need improvement. International Family Planning Perspectives, 2005, 31(3):140-149

Illegal or clandestine abortion has been a relatively neglected issue, in spite of being recognized as an important component of reproductive health and rights since the 1994 International Conference on Population and Development. An estimated 19 million unsafe abortions take place worldwide each year-almost all of those occurring in the developing world. ${ }^{1}$ The conditions under which such abortions take place result in serious consequences for women and societies: For example, $13 \%$ of maternal deaths in the developing world are attributed to unsafe abortions. ${ }^{2}$ In addition, large costs are incurred by public sector health care systems because of the provision of medical care to women suffering from abortion complications. However, insufficient information at the country level perpetuates the invisibility of the problem and results in governments giving little priority in policy decisions to improving services for postabortion care or to expanding contraceptive services to reduce unplanned pregnancy.

In countries like the Philippines, where induced abortion is against the law, ${ }^{3 *}$ many women nevertheless seek an abortion-despite conditions that may put their health at risk-rather than give birth to children they cannot care for or do not want. A study using an indirect methodology estimated that in 1994, there were 400,000 induced abor-

*The penal code regarding abortion contains a general prohibition on abortion. Although no exceptions are specified, it may be interpreted to permit abortion to save the life of a pregnant woman (see reference 3 ). tions in the country and 80,000 women hospitalized for complications of induced abortion. ${ }^{4}$ The Department of Health of the Philippines reported that $12 \%$ of all maternal deaths in 1994 were the result of illegal abortion. ${ }^{5}$

Studies from the 1970s onward have shown that despite the law's severity, abortion appears to be widely practiced. ${ }^{6}$ Evidence from the mid-1990s indicates that Filipino women of all social classes and backgrounds are having induced abortions. ${ }^{7}$ They do so under varying circumstances, ranging from safe medical procedures performed for better-off women by trained personnel to procedures in extremely unsafe conditions for poor women who cannot afford to pay for a surgical abortion. The evidence of a survey of health professionals in the mid-1990s suggests that about one-third of women seeking an abortion obtain it from a doctor or nurse, but a high proportion of women consult traditional practitioners or attempt to induce the abortion themselves. ${ }^{8}$

Regrettably, because induced abortion is punishable by law in the Philippines, the subject tends to be masked by silence and consequently, public attention to the issue is minimal. The general secrecy surrounding induced abortion does not mean, however, that the subject has not been of concern over the past 30 or more years. A number of medical professionals, lawyers, social scientists, legislators and women's health advocates, among others, have written on the subject and worked toward improving health policies 
and services. In addition, the Philippines Department of Health provided official guidelines for a postabortion care program, Prevention and Management of Abortion and its Complications, and pilot tested such programs in 17 government hospitals by late 2003. ${ }^{9}$

Given the likelihood of changes over the past 10 years in fertility preferences, contraceptive use and abortion methods, it is of great relevance to know how these changes have affected the levels of unintended pregnancy and induced abortion, as well as the safety of induced abortion in the Philippines. For example, has the level of unintended pregnancy increased over the past decade? What have been the national and regional trends? And has the number of women hospitalized for abortion complications declined as abortion methods have changed? In addition, national survey data show that contraceptive use increased only moderately between 1993 and 1998, and that in some regions, use of modern methods hardly increased. ${ }^{10}$ The proportion of all live births that are unplanned remained at about 45\% between 1993 and 2003, while the gap between actual family size and wanted family size remained at about one child per woman. ${ }^{11}$ Might these trends be related to an increase in unintended pregnancy and abortion, as women continue to experience difficulties in obtaining modern contraceptive methods and in achieving the family size they want?

The aim of this article is to address some of these questions by providing new estimates of abortion in the Philippines for the year 2000, and by assessing abortion trends between 1994 and 2000. We provide estimates of the number of women who were hospitalized in 2000 for the treatment of complications following unsafe induced abortions; the total number of women who had induced abortions each year, including both women who experienced no complications from the procedure and those who did; and the incidence of induced abortion at national and regional levels. We apply the same indirect estimation methodology used for our earlier study and, therefore, have comparable estimates for 2000, allowing assessment of change in the level of induced abortion between 1994 and 2000.

Also, for the first time, we estimate unintended pregnancy rates for the Philippines by combining our estimate of induced abortion with an estimate of the number of unplanned births based on available national survey data on the planning status of recent births. We provide estimates of unintended pregnancy rates and the proportion of pregnancies that are unintended for both 1994 and 2000, nationally and for the four major regions of the country. These data provide insights into trends in the root causes of unintended pregnancy and abortion, and increase our understanding of the factors underlying the level, differentials and trends in induced abortion, including contraceptive use.

\section{METHODS}

Estimating the level of abortion in the Philippines involved several steps: collecting information on the number of women hospitalized due to abortion complications, ad- justing this number for incompleteness, separating out women treated for complications of induced abortion and calculating the total number of women having an induced abortion-safe or unsafe-based on the number of women hospitalized. We arrived at these assumptions after considering all available information concerning the safety of abortion practice and access to hospitals. These data were then used to estimate the abortion rate and the abortion ratio. Data on abortion were combined with survey-based data on total births and unplanned births to estimate total and unintended pregnancy rates.

\section{Data}

As part of licensing regulations, all hospitals in the Philippines are required to submit an annual report to their regional Department of Health office that includes the number of patients treated for each of the top 10 causes of hospital admission. Although regional health offices are expected to submit these forms to the national office in Manila, not all do so. Furthermore, the regional offices that do submit the forms sometimes have not received records for all hospitals in their region. Although they are used for basic summary findings on health care provision, the hospital reports are not compiled, processed or tabulated at the national level to allow for a detailed analysis of abortion-related hospitalization. As a result, part of the work of the present study was to collect available forms for all hospitals in the Philippines between 1996 and 2001, starting with the records available at the central Department of Health office, and then obtaining those from each of the 16 regional health offices. Between May 2003 and February 2004, we identified a total of 2,039 hospitals in the Philippines and obtained usable reporting forms for 1,658 facilities. Reports were obtained for $81 \%$ of hospitals, representing $89 \%$ of hospital beds, indicating that coverage was very high (not shown).

The sources of data on contraceptive use, planning status of births and unmet need for contraceptive services are two national surveys, the 1993 National Demographic Survey (1993 DHS) and the 1998 National Demographic and Health Survey (1998 DHS). In the 1993 DHS, 15,029 women aged 15-49 were interviewed, and in the 1998 DHS, 13,983 women were interviewed. Also, we cite recently released findings for the 2003 DHS survey, in which 13,633 women were interviewed.

\section{Estimating Abortion Incidence}

Several methodological approaches have been developed to estimate levels of abortion, but all suffer from high levels of underestimation. ${ }^{12}$ We chose to use the indirect methodology developed for the 1994 study based on hospital records ${ }^{13}$ for several reasons. First, this methodlogy allows assessment of trends by providing comparable measures of incidence for both points in time. Second, it provides estimates not only at the national level, but also for the four major regions-metropolitan Manila (also known as the National Capital Region), the rest of Luzon, Visayas 


$\begin{aligned} & \text { TABLE 1. Measures related to calculating the number of women hospitalized for abortion complications; and estimated num- } \\
& \text { ber of induced abortions, by multiplier to account for women not hospitalized for abortion complications-all according to } \\
& \text { area, Philippines, }\end{aligned}$
\begin{tabular}{|l} 
2000 \\
Area
\end{tabular}
$\begin{aligned} & \text { No. of } \\
& \text { women } \\
& \text { aged 15-44 }\end{aligned}$

*Calculations were completed separately for each of the country's 16 regions and then summed to obtain results for the four major areas. $†$ All hospitalizations minus hospitalizations for spontaneous abortion. Note: In this and subsequent tables, Metro Manila refers to the National Capital Region.

and Mindanao).* Third, it provides an estimate of serious abortion morbidity (that is, the number of women hospitalized for abortion complications). Finally, it provides for adjustment for underreporting, unlike most other methods. To account for some years' incomplete data and for likely actual year-to-year fluctuations, we calculated estimates based on averaged data for 1999-2001, producing estimates for the central year, 2000.

- Calculating the total number of women hospitalized for abortion. We used a three-step methodology to estimate the number of women treated for abortion complications in all hospitals, including those for which these data were not directly reported. For hospitals that reported abortion as one of the 10 leading causes of admission, we obtained the number from the hospital reports. For hospitals at which abortion did not rank among the top 10 reported causes, we assumed that admissions for abortion complications accounted for half as many patients as the number hospitalized for the lowest or 10th-ranking cause..$^{\dagger}$ For all other hospitals (i.e.,

*Manila, the capital city, has 9.9 million inhabitants; the rest of Luzon is 48\% urban, with a total population of 32.9 million; Visayas has a population of 15.5 million, of which 34\% live in urban areas; and Mindanao has 18.1 million people, $32 \%$ of whom live in urban areas.

†Several factors underlie this assumption. According to health professionals, abortion complications are widespread and treated in almost all hospitals. In the hospital reports, abortion complication cases may be shown in several diagnosis codes, and often no single code ranks within the top 10 causes of discharge, although the total number of patients treated for abortion complications is likely to be substantial. Assuming that half of the number of cases in the lowest of the 10 top causes reflects the fact that the number of abortion cases will range from zero up to the number in the 10th ranking cause.

¥Characteristics included ownership (public or private), hospital level (primary, secondary or tertiary), hospital size (number of beds) and region (the detailed 16-region classification)

$\S$ In the text, we round estimates to the nearest 100; data shown in the tables are unrounded.

**Although some women who have miscarriages before 12 weeks' gestation may seek medical care, many do so on an outpatient basis, and relatively few are hospitalized. Pregnancy losses at 22 weeks or later are not considered because they are usually classified as fetal deaths.

t+We estimated the number of births for 2000 , nationally and for the four major regions, by multiplying the detailed regional age-specific fertility rates (ASFRs) from the Philippines 2003 Demographic and Health Survey (estimates were provided by the National Statistical Office, prior to release of the data for public use) by the female population aged 15-44 in fiveyear age-groups (from the 2000 census). The ASFRs refer to the three-year period before interview and, therefore, approximate the reference year for our abortion estimates. those that did not file a report or omitted data on abortion complications), we entered hospital characteristics ${ }^{\ddagger}$ into a logistic regression to impute the number from hospitals with information.

In 478 hospitals-about one in four-abortion was one of the 10 main causes of admission, so a direct count of the number of women hospitalized for abortion complications was available from their official reports. For these facilities, there were approximately 71,500 annual hospitalizations for complications of induced and spontaneous abortion; $\$$ the average annual number of cases treated was 150 , and the range was 1 to 3,748. We estimated that 26,500 women were hospitalized for abortion complications each year in the remaining 1,180 hospitals at which abortion was not among the top 10 causes, and 7,000 women were hospitalized in the 381 hospitals that had no submitted report. Therefore, we estimated that a total of 105,000 women were hospitalized for abortion complications in 2000 (Table 1).

- Estimating the number of women hospitalized for induced abortion. Some of the women hospitalized for abortion complications had been admitted after having a spontaneous abortion. We needed to subtract these women from the total to estimate the number hospitalized for complications of induced abortion. Data reported by hospitals, however, typically do not distinguish between induced and spontaneous abortions, both because symptoms are often similar and because of a reluctance to expose patients to possible legal action. For these calculations, we used data on the biological pattern of spontaneous abortion, established by clinical studies, ${ }^{14}$ and assumed that late miscarriages (those at 13-22 weeks) are likely to require hospital care. ${ }^{* *}$ Miscarriages at $13-22$ weeks account for about $2.9 \%$ of all recognized pregnancies, and are equal to $3.4 \%$ of all live births. ${ }^{\dagger \dagger}$ A final adjustment is needed because only a certain proportion of all women who need hospital care for the treatment of late spontaneous abortion will have access to a hospital or use hospital services for this condition. We assumed this proportion to be the same as the proportion of women giving birth who deliver in a hospital: Nationally, $37 \%$ of women delivered at a health facility, $73 \%$ in Manila, 36\% in the rest of Luzon, 29\% in Visayas and 23\% in Mindanao. ${ }^{15}$ Applying these assumptions within regions, we estimate that 26,100 women were hospitalized 
for complications of spontaneous abortion in 2000.

- Estimating the total number of induced abortions. Next, we derived a multiplier, or inflation factor, to estimate the total number of women who had an abortion in the Philippines in 2000. This total would include women who had a complication but did not obtain hospital care (whether due to poor access to hospitals or to a reluctance to seek treatment), those who obtained care from a private doctor, those who died before obtaining hospital care and those who had an uncomplicated abortion. Multiplying the number of women hospitalized because of an induced abortion by the inflation factor would provide an estimate of the total number of women who had an abortion in 2000.

In general, the safer abortion services are, the higher the multiplier, because for every woman hospitalized, many have abortions that do not result in complications or hospitalizations. Concomitantly, the more risky the abortion services are in a given setting, the lower the multiplier, because a higher proportion of women have serious complications that need hospital care. Safety is not the only consideration, however. The multiplier is also a function of the accessibility of hospital services. Where such services are easily accessible, the proportion of women with complications who receive hospital treatment will be higher. In poor regions or in underdeveloped rural areas, on the other hand, where there are few hospitals, some of the most seriously affected women may not get the treatment they need.

Unfortunately, there have been no recent large-scale, community-based surveys in the Philippines that might provide a reasonable estimate of the proportion of all women having induced abortions who are hospitalized. Therefore, we used existing estimates. We drew upon two sources: the body of evidence used by the 1997 study by Singh and colleagues that developed estimates of the level of abortion in the Philippines in $1994^{16}$ and anecdotal evidence of changes in abortion service provision since the mid-1990s. Two Philippine community surveys provided relevant information. In one, conducted in 1978 in Cavite province, 12\% of women who reported having had one or more abortions had been hospitalized for complications. ${ }^{17}$ The other, conducted in 1994, found that among 170 women in Manila who reported ever having had an abortion, about $36 \%$ had been hospitalized for complications. ${ }^{18}$ Still, neither of these studies is likely to be generalizable to the whole country or to 1999-2001, the time period of the present estimate.

A third source of information is a 1996 survey of health professionals suggesting that about one in four women who had had an induced abortion were expected to be hospitalized as a result of complications. ${ }^{19}$ On the basis of this body of data, the 1997 study by Singh and colleagues concluded that a multiplier of five was appropriate for the Philippines in the mid-1990s, given the conditions of abortion service provision that existed at that time.

However, in estimating the multiplier, it was important that we consider evidence of increasingly safe abortion services in the 1990s, even within the highly legally restricted context. There is anecdotal evidence that the number of clinics offering safe surgical procedures has increased. ${ }^{20}$ In these clinics, obstetrician-gynecologists train and supervise nurses and midwives in performing abortions, and almost all patients come through referral. ${ }^{21}$ In addition, the trend in the 1990s of increased use of misoprostol and other drugs to cause abortion is apparently continuing. ${ }^{22}$ Misoprostol is highly effective, ${ }^{23}$ and has been available inexpensively on the Philippine black market for some years now. ${ }^{24}$ Preliminary results from a 2004 qualitative study in Manila and suburbs show that use of misoprostol was indeed very common, with 20 out of 66 abortion attempts being made with this method, either alone or in combination with other methods. ${ }^{25}$

The limited information available on recent trends and current conditions of abortion service provision, including the cost constraints faced by poor women, leads us to conclude that the safety of abortion has likely improved over the last decade. As a result, the proportion needing hospitalization among all women obtaining an abortion has probably declined, thus increasing the multiplier used to estimate the total number of abortions from the number of women hospitalized from complications of such abortions. We estimate, therefore, that for 2000 the multiplier likely ranges between five and seven (that is, between one in five and one in seven women having an induced abortion were hospitalized for complications).

We present estimates for 2000 based on three multipliers $-5,6$ and 7. To assess trends over the recent period, 1994-2000, we base estimates for 2000 on the medium estimate, calculated using a multiplier of 6 , and compare them with the medium estimates for 1994. It is important to bear in mind that access to safe abortion and to hospitals varies across areas and subgroups, thus requiring a higher or lower multiplier to produce a reasonably accurate estimate; however, available information does not permit estimation of regional-level multipliers.

\section{Estimating Unintended Pregnancy}

Calculation of unintended pregnancy numbers and rates involved several steps. We estimated the annual number of births by applying age-specific fertility rates for each major region (calculated from 1993 and 2003 DHS data) to population estimates for five-year age-groups of women for 1994 and 2000, respectively. The population estimates are from the National Statistical Office of the Philippines, and were either interpolated between censuses (for 1994) or directly obtained from the census (for 2000). We obtained the number of births for 2000 by prorating the rate of change in fertility between 1993 and 2003, and adjusting the 2000 numbers based on fertility levels from the 2003 survey. Separately, we obtained the proportion of births that are unplanned-mistimed or unwanted at the time they were conceived-from national surveys for 1993 and 1998, and applied these to the fertility estimates to obtain the rate of unplanned births. These are combined with the abortion rate to provide an estimate of the rate of unintended pregnancy for 1994 and 2000. 


\begin{tabular}{|c|c|c|c|c|c|c|}
\hline \multirow[t]{2}{*}{ Area } & \multicolumn{3}{|c|}{ Abortion rate } & \multicolumn{3}{|c|}{ Abortion ratio } \\
\hline & 5 & 6 & 7 & 5 & 6 & 7 \\
\hline Philippines & 22 & 27 & 31 & 16 & 18 & 21 \\
\hline Metro Manila & 43 & 52 & 60 & 31 & 35 & 38 \\
\hline Rest of Luzon & 23 & 27 & 32 & 16 & 18 & 21 \\
\hline Visayas & 14 & 17 & 19 & 10 & 11 & 13 \\
\hline Mindanao & 15 & 18 & 21 & 10 & 12 & 14 \\
\hline
\end{tabular}

Notes: The abortion rate is the number of abortions per 1,000 women aged 15-44 per year. The abortion ratio is the number of abortions per 100 pregnancies (the sum of abortions and births).

\section{RESULTS}

\section{Abortion Morbidity}

By subtracting the estimated annual number of women hospitalized for complications of spontaneous abortions $(26,100)$ from the estimated annual number of women hospitalized for complications of abortions $(105,000)$, we calculated that in 2000, approximately 78,900 women were hospitalized for complications of induced abortion (Table 1). That translates to a national rate of 4.5 per 1,000 women of reproductive age per year (not shown). Manila had a much higher rate (8.6), probably because of better access to hospitals. The rate in the rest of Luzon was the same as the national average, whereas the rates in Visayas and Mindanao were lower (2.8 and 3.0, respectively), most likely because of poor access to hospital care. The national abortion hospitalization rate declined between 1994 and 2000, from 5.0 to 4.5 per 1,000 women-a change most likely resulting from increased use of safer abortion methods rather than a decline in abortion incidence.

\section{Abortion Incidence in $\mathbf{2 0 0 0}$}

The medium 2000 estimate for the total number of induced abortions in the Philippines is 473,400 (Table 1); the low estimate is 394,500 , and the high estimate is 552,300 . The medium estimate for the abortion rate is 27 induced abortions per 1,000 women aged 15-44 per year (Table 2); the low estimate is 22 , and the high estimate is 31 . There is considerable variation in the medium estimated abortion rate for the different areas of the country. Manila and the rest of Luzon, which are more urban than the other regions, have higher abortion rates (52 and 27 , respectively) than do Visayas and Mindanao (17 and 18, respectively).

\begin{tabular}{|c|c|c|c|c|c|c|}
\hline \multirow[t]{2}{*}{ Area } & \multicolumn{2}{|c|}{$\begin{array}{l}\text { No. of women hospitalized } \\
\text { for induced abortion }\end{array}$} & \multicolumn{2}{|c|}{$\begin{array}{l}\text { No. of induced } \\
\text { abortions }\end{array}$} & \multicolumn{2}{|c|}{ Abortion rate } \\
\hline & 1994 & 2000 & $1994^{*}$ & $2000 \dagger$ & $1994^{*}$ & $2000+$ \\
\hline Philippines & 80,103 & 78,901 & 400,515 & 473,408 & 25 & 27 \\
\hline Metro Manila & 20,917 & 23,309 & 104,585 & 139,853 & 41 & 52 \\
\hline Rest of Luzon & 38,899 & 34,018 & 194,495 & 204,105 & 30 & 27 \\
\hline Visayas & 6,895 & 9,337 & 34,475 & 56,022 & 11 & 17 \\
\hline Mindanao & 13,392 & 12,238 & 66,960 & 73,427 & 18 & 18 \\
\hline
\end{tabular}

Using the medium multiplier, we estimated that the national abortion ratio in 2000 was 18, meaning that 18 of every 100 pregnancies (live births and abortions) ended in abortion; the low estimate is 16 and the high estimate is 21. Thus, approximately one in five pregnancies is terminated by induced abortion. According to estimates for the four major regions, Manila has the highest proportion of pregnancies ending in abortion (one in three), compared with about one in five in the rest of Luzon and about one in eight in Visayas and Mindanao.

\section{Trends in Abortion, 1994-2000}

Nationally, the annual number of women hospitalized due to induced abortion declined by 2.5\% between 1994 and 2000 , from about 80,100 to 78,900 (Table 3); however, the numbers for Manila and Visayas increased by $11 \%$ and 35\%, respectively, during that time. Based on medium estimates, 400,500 women nationwide had an induced abortion in 1994; this number increased to 473,400 in 2000. Although the absolute number of induced abortions increased in all regions, Manila and Visayas had much larger increases (34\% and $63 \%$, respectively) than did the rest of Luzon and Mindanao ( $5 \%$ and $10 \%$, respectively).

The national induced abortion rate remained nearly stable between 1994 ( 25 per 1,000) and 2000 (27 per 1,000). Nevertheless, a relatively large increase in the abortion rate occurred in two regions. In Manila, the abortion rate rose by $25 \%$, from an already high rate of 41 to 52 per 1,000 . And in Visayas, the rate increased by 54\%, from 11 to 17 per 1,000 .

\section{Abortion in the Context of Unintended Pregnancies}

To portray the broader context in which induced abortion occurs in the Philippines, we estimated the proportion of births that are unplanned, the overall pregnancy rate, the proportion of pregnancies that are unintended and the unintended pregnancy rate. First, we drew estimates from the 1993 DHS and the 1998 DHS of the proportion of live births that were unwanted or mistimed at the time the women became pregnant. In 1993, 16\% of births in the Philippines were unwanted (Table 4); this proportion increased to $18 \%$ in 1998. The proportion of mistimed births was virtually unchanged between 1993 and 1998 (28\% and 27\%, respectively), as was the proportion of unplanned births (44\% and $45 \%$, respectively).

In 1993, the proportion of unplanned births varied widely across regions, from a low of $31 \%$ in Manila to a high of 55\% in Visayas. However, between 1993 and 1998, trends were quite different by region, and by 1998, the proportion of unplanned births was similarly high across regions (42-48\%). In Manila, the proportion of unplanned births increased by $50 \%$ during the period, from $31 \%$ to $47 \%$. By comparison, Mindanao and the rest of Luzon had small increases in unplanned births ( $8 \%$ and $1 \%$, respectively), and Visayas had a moderate decrease (14\%).

The estimate of unplanned births combined with the estimate of abortions can be used to calculate unintended 
TABLE 4. Percentages of live births that were unwanted, mistimed and unplanned at the time the woman became pregnant, by year, according to area*

\begin{tabular}{lll|ll|ll|} 
Area & \multicolumn{2}{l|}{ Unwanted } & \multicolumn{2}{c|}{ Mistimed } & \multicolumn{2}{c}{ Unplanned } \\
\cline { 2 - 7 } & 1993 & 1998 & 1993 & 1998 & 1993 & 1998 \\
\hline Philippines & $\mathbf{1 5 . 9}$ & $\mathbf{1 8 . 0}$ & $\mathbf{2 8 . 0}$ & $\mathbf{2 7 . 3}$ & $\mathbf{4 4 . 0}$ & $\mathbf{4 5 . 4}$ \\
Metro Manila & 13.8 & 15.8 & 17.5 & 31.1 & 31.3 & 46.8 \\
Rest of Luzon & 16.7 & 15.8 & 25.1 & 26.5 & 41.8 & 42.3 \\
Visayas & 20.2 & 23.6 & 34.4 & 23.2 & 54.6 & 46.9 \\
Mindanao & 12.1 & 18.1 & 32.6 & 30.2 & 44.7 & 48.4
\end{tabular}

*Based on live births in the five-year period prior to the interview. Source: reference 11 .

pregnancies. The proportions of births that are unplanned based on the five-year period before each survey year were applied to the total number of live births in 1994 and 2000. We assumed that this proportion remained approximately the same from the early 1990s to 1994 and from the midto late-1990s to 2000. Nationally, the unintended pregnancy rate remained stable between 1994 and 2000 (83 and 81 unintended pregnancies per 1,000 women per year, respectively-Table 5). The rate for Manila, however, increased by $43 \%$ during that time (from 68 to 97 unintended pregnancies per 1,000 women per year), whereas other regions' rates declined. The proportion of all pregnancies that are unintended changed little in the Philippines between 1994 and 2000 (53\% and 55\%, respectively). Again, the largest change in the proportion of pregnancies that are unintended occurred in Manila, rising from 54\% to $65 \%$, whereas the proportions in the other regions changed more modestly or remained about the same.

Finally, we calculated the overall pregnancy rate for the Philippines. The pregnancy rate declined by $6 \%$ between 1994 and 2000-from 156 to 147 pregnancies per 1,000 women per year. Manila experienced a substantial increase (18\%) in the pregnancy rate-from 127 to 149 , resulting from an increase in both fertility and abortion during the 1990s. Because of these trends, Manila went from having the lowest pregnancy and unintended pregnancy rates of the regions in 1994 to having the highest of both in 2000. The other three regions experienced $8-10 \%$ declines in the pregnancy rate. With these different trends, the pregnancy rate by 2000 was similar across the four regions, ranging from 145 to 149 .

\section{Factors Underlying Trends in Pregnancy and Abortion}

The observed differences in levels and trends among the four major regions in unintended pregnancy and abortion may be explained by factors such as increased exposure to the risk of pregnancy, decreased contraceptive use, a shift toward use of traditional contraceptive methods instead of modern methods or decreased effective use of contraceptives. One indicator of an increased risk of conception-the gap between age at menarche and age at first union-has changed little between the early 1990s and 2003, although

*The most widely used methods in 1998 were the pill (10\%) and female sterilization (10\%), followed by periodic abstinence ( $9 \%$ ) and withdrawal (9\%). the change is in the direction of increased risk. ${ }^{26}$ And although trend data are not available, reported levels of sexual activity among unmarried women are low: About 9\% of single women 15-24 report having ever had intercourse, according to a 1994 nationally representative survey. ${ }^{27}$

Available data, however, suggest that changing levels and patterns of contraceptive use may have affected levels of unintended pregnancy and abortion. Current contraceptive prevalence among married women 15-49 increased from 40\% in 1993 to 48\% in 1998 (Table 6, page 146); however, use of modern methods increased from $25 \%$ to $28 \%$ during that time, while use of traditional methods-which are likely to have high failure rates-rose from 15\% to 20\%.* In addition, contraceptive users are experiencing increased difficulties in maintaining continuous protection, given that $44 \%$ of pill users discontinue the method within a year of adopting it (an increase of 33\% from 1993). ${ }^{28}$

Regional trends sometimes differ from the national trend. Between 1993 and 1998, the level of modern contraceptive use in Manila remained relatively unchanged, whereas the rest of Luzon and Mindanao experienced increases of 4-5 percentage points, or almost 20\%. The proportion of women using traditional methods increased in all regions, but most substantially in Manila (from 15\% to 22\%), followed by Visayas (from 17\% to 23\%).

However, the proportion of married women with an unmet need for effective contraception in the late 1990s was extremely high: One of every two married women did not want a child soon or wanted no more children, but were not using a contraceptive method. The overall proportion of married women who have an unmet need for contraception dropped slightly between 1993 and 1998 (from $54 \%$ to $50 \%$ ); however, this was due to substantial declines in the proportions in the rest of Luzon and Mindanao, while the proportions in Visayas and Manila changed little.

\section{DISCUSSION}

The consequences of unsafe abortion for women's health and survival in the Philippines are evident from the large numbers being treated each year for abortion-related complications. Moreover, this number increased in Manila and Visayas during the 1990 s. ${ }^{29}$ Given the fact that substantial

\begin{tabular}{|c|c|c|c|c|c|c|c|c|}
\hline \multirow[t]{2}{*}{ Area } & \multicolumn{2}{|c|}{ No. of pregnancies } & \multicolumn{2}{|c|}{$\begin{array}{l}\text { Unintended } \\
\text { pregnancy } \\
\text { rate* }^{*}\end{array}$} & \multicolumn{2}{|c|}{$\begin{array}{l}\% \text { of pregnancies } \\
\text { that are } \\
\text { unintended } t\end{array}$} & \multicolumn{2}{|c|}{$\begin{array}{l}\text { Pregnancy } \\
\text { rate } \neq\end{array}$} \\
\hline & 1994 & 2000 & 1994 & 2000 & 1994 & 2000 & 1994 & 2000 \\
\hline Philippines & $2,507,501$ & $2,607,669$ & 83 & 81 & 53 & 55 & 156 & 147 \\
\hline Metro Manila & 320,720 & 403,060 & 68 & 97 & 54 & 65 & 127 & 149 \\
\hline Rest of Luzon & $1,060,492$ & $1,108,271$ & 85 & 78 & 52 & 53 & 161 & 148 \\
\hline Visayas & 500,809 & 494,064 & 91 & 78 & 58 & 53 & 157 & 146 \\
\hline Mindanao & 625,479 & 602,274 & 84 & 80 & 51 & 55 & 166 & 145 \\
\hline
\end{tabular}

*Unintended pregnancy rate $=(\%$ unintended births $x$ general fertility rate $)+$ abortion rate. + Percentage of pregnancies that are unintended=unintended pregnancy rate/pregnancy rate 100 . $\neq$ Pregnancy rate $=$ general fertility rate + abortion rate. Note: We assume that the age-specific fertility rates and the intention status of births obtained from the 1993 and 1998 Demographic and Health Surveys apply to the years 1994 and 2000, respectively. 
TABLE 6. Percentage of currently married women aged 15-49 reporting current contraceptive use, by method type and year; percentage of all contraceptive users who used traditional methods, by year; and percentage of currently married women with an unmet need for contraception, by year-all according to area

\begin{tabular}{|c|c|c|c|c|c|c|c|c|c|c|}
\hline \multirow[t]{3}{*}{ Area } & \multicolumn{6}{|c|}{ Currently married women 15-49 } & \multicolumn{2}{|c|}{$\begin{array}{l}\text { \% who used tradi- } \\
\text { tional methods }\end{array}$} & \multicolumn{2}{|c|}{$\begin{array}{l}\% \text { of married women } \\
\text { with unmet need }\end{array}$} \\
\hline & \multicolumn{2}{|l|}{ Any } & \multicolumn{2}{|c|}{ Modern } & \multicolumn{2}{|c|}{ Traditional } & \multirow[t]{2}{*}{1993} & \multirow[t]{2}{*}{1998} & \multirow[t]{2}{*}{1993} & \multirow[t]{2}{*}{1998} \\
\hline & 1993 & 1998 & 1993 & 1998 & 1993 & 1998 & & & & \\
\hline Philippines & 40.0 & 47.8 & 24.8 & 28.0 & 15.1 & 19.8 & 37.9 & 41.4 & 53.7 & 50.3 \\
\hline Metro Manila & 41.9 & 50.4 & 27.3 & 28.5 & 14.6 & 21.9 & 34.9 & 43.5 & 47.9 & 48.5 \\
\hline Rest of Luzon & 38.8 & 47.7 & 24.6 & 29.2 & 14.1 & 18.5 & 36.5 & 38.9 & 52.6 & 49.1 \\
\hline Visayas & 41.4 & 47.3 & 24.3 & 24.2 & 17.1 & 23.1 & 41.3 & 48.8 & 56.5 & 56.1 \\
\hline Mindanao & 39.8 & 46.9 & 24.3 & 29.0 & 15.6 & 17.8 & 39.1 & 38.0 & 56.7 & 49.0 \\
\hline
\end{tabular}

Source: reference 11

proportions of women who have complications do not receive treatment at a medical facility, the estimated annual rate of 4.5 per 1,000 women most likely underestimates the size of this problem. In addition, treatment of abortion complications absorbs scarce medical resources and incurs large costs to the public health system. Furthermore, studies suggest that the quality of such postabortion care is poor: Women seeking care at hospitals for complications of induced abortions are often viewed as criminals and verbally admonished. In some cases, they are denied anesthesia and made to wait longer than other patients thought to be suffering from spontaneous abortion. ${ }^{30}$

The almost half a million induced abortions occurring each year in the Philippines cannot be understood in isolation from the generally restrictive social and political climate surrounding the delivery of modern contraceptive services. In addition, decentralization of health service provision most likely contributes to Filipino women's difficulties in obtaining contraceptive information, services and supplies. Moreover, husbands' negative attitudes toward family planning ${ }^{31}$ and women's misperceptions about the side effects of methods ${ }^{32}$ may prevent women from practicing contraception.

One factor that has serious implications for the risk of unintended pregnancies and abortions is Filipino women's heavy reliance on traditional contraceptive methods. Withdrawal and periodic abstinence-which are commonly used in Philippines ${ }^{33}$-typically have higher failure rates than do modern methods such as sterilization and the pill. ${ }^{34}$ Also, the majority of women using periodic abstinence do not know the timing of their fertile period, thus further increasing their risk of unintended pregnancy and possibly of induced abortion. ${ }^{35}$

Another factor contributing to unintended pregnancy and abortion is the deficiencies in the family planning services available in the Philippines. ${ }^{36}$ According to a study focusing on the quality of family planning services for new mothers in 28 provinces across the country, a surprisingly large proportion of clinics did not provide any advice on contraception to women who wished to stop having children, and that proportion increased between 1994 and $1997 .{ }^{37}$ In addition, service providers incorrectly informed clients that the duration of the protective period from breastfeeding (i.e., lactational amenorrhea) is longer than it actually is.

The Catholic Church in the Philippines is likely to have had a strong influence on the provision of contraceptive services, given that it opposes use of modern contraceptive methods. The church accepts only periodic abstinence as a method of family planning. ${ }^{38}$ It was critical of the Ramos administration, which promoted the use of artificial or modern birth control methods, and have campaigned against politicians who support modern family planning. Under President Macapagal-Arroyo, the national population and reproductive health program has endorsed traditional family planning methods on the grounds that they promote family values.

Another important factor that may have negatively influenced the provision of family planning services is the process of decentralization (i.e., the transfer of power from the central government to local levels of administration) that began in 1991. Until this study, there had not been any assessment of the likely effect of devolution on provision of contraceptive services. However, it is possible that variation in support for family planning services at the local level may partly explain our findings of decreased use of modern contraceptives, increased use of traditional methods and an increased level of induced abortion in some regions. In particular, the unexpected finding that women living in Manila-the most urbanized area of the country, where family planning services would be expected to be widely available and accessible-have high and increasing levels of unintended pregnancy and abortion than other regions may be partly because of reduced supplies of modern methods and declines in access to contraceptive services. The explicit position taken by the Atienza administration in the City of Manila banning any artificial methods of contraception from being offered in any public clinic under its direct control and supervision likely also increased barriers to services.

According to newly available data for 2003, the level of contraceptive use in the Philippines increased only slightly between 1998 and 2003;39 a small but important shift toward increased use of modern methods occurred during that time, accompanied by a decline in use of traditional methods. Thus, while overall use was 48\% in 1998 and 49\% 2003, the proportion using modern methods increased from $28 \%$ to $33 \% .{ }^{40}$ In Manila, overall use remained sta- 
ble at $49-50 \%$, but modern method use increased from $29 \%$ to $32 \%$, similar to the national pattern.

This study has several policy and programmatic implications. An estimated 78,900 Filipino women are hospitalized each year for abortion complications. Given that many more women, particularly those in the rural regions of Visayas and Mindanao, are probably in need of postabortion care but cannot obtain it, services should be made more widely available, especially in rural and isolated areas, and health care providers should receive comprehensive training in postabortion services and family planning counseling. Adequate postabortion care services and counseling should be offered at all public provincial and district hospitals. Also, in light of reports of judgmental behavior toward postabortion patients, ${ }^{41}$ training programs should include sensitization of health providers about the context and realities of women who obtain unsafe abortions.

The second important area in which improvements in policy and programs are needed concerns provision of contraceptive services and information to the general population and to specific subgroups, such as adolescents and men. Better services would improve the ability of women to prevent unintended pregnancy and thereby reduce the level of induced abortion overall, as well as reduce unsafe abortion and its consequences on women's health in the Philippines. Not only do women hospitalized for abortion complications need contraceptive counseling and services, but the approximately one in two married women of reproductive age who have an unmet need for effective contraception need improved contraceptive services-including an expanded range of contraceptive methods and improved quality of services.

Couples should be better educated on the advantages of using modern effective contraceptive methods and on side effects, as well as on how to minimize the risk of incorrect or inconsistent method use. Providers need training to improve and update their knowledge of the efficacy, advantages and disadvantages of all contraceptive methods. Considering the important role of husbands and partners in decision making about family size and contraceptive use, efforts should be made to provide information to husbands and male partners directly, as well as include them to the extent possible when their wives make family planning visits.

\section{REFERENCES}

1. Åhman E and Shah I, Unsafe abortion: worldwide estimates for 2000, Reproductive Health Matters, 2002, No. 19, pp. 13-17.

2. Åhman E and Shah I, Unsafe Abortion: Global and Regional Estimates of the Incidence of Unsafe Abortion and Associated Mortality in 2000, fourth ed., Geneva: World Health Organization, 2004.

3. United Nations Department of Economic and Social Development, Abortion Policies: A Global Review, Vol. III, New York: United Nations, 1995.

4. Singh S et al., Estimating the level of abortion in the Philippines and Bangladesh, International Family Planning Perspectives, 1997, 23(3):100$107 \& 144$.

5. Shire A and Pesso L, Changing policies and attitudes: postabortion care in the Philippines, Compass, 2003, No. 1, pp. 1-4.

6. Ramosa-Jalbuena J, Baltazar JC and Villamosa CR, Septic abortion: a report on 709 cases, Journal of the Philippine Medical Association, 1978,
54(5-6):185-197; Ramoso-Jalbuena J and Ladines-Llave C, Septic abortion: a five-year review at the Philippine General Hospital (1979-1983), Philippine Journal of Obstetrics and Gynecology, 1988, 12(4):143-155; Raymundo CR, Zablan ZC and Cruz GT, Abortion: A Public Health Concern, Quezon City, Philippines: University of the Philippines Population Institute, 1996; Perez AE et al., Clandestine Abortion: A Philippine Reality, New York: The Alan Guttmacher Institute (AGI), 1997; and Raymundo C et al., Unsafe Abortion in the Philippines: A Threat to Public Health, Quezon City, Philippines: Demographic Research and Development Foundation, University of the Philippines Population Institute, 2001

7. Raymundo C et al., 2001, op. cit. (see reference 6).

8. Singh S, Wulf D and Jones H, Induced abortion in South Central and Southeast Asia: results of a survey of health professionals, International Family Planning Perspectives, 1997, 23(2):59-67.

9. Ellen Bautista, Engenderhealth, Manila, Philippines, personal communication, May 9, 2005.

10. Singh $S$ and Juarez F, Improving reproductive health in the Philippines, Research in Brief, New York: AGI, 2003.

11. National Statistical Office (NSO) and Macro International, Philippines National Demographic and Health Survey, 1993, Calverton, MD, USA: Macro International, 1994; and NSO and ORC Macro, Philippines National Demographic and Health Survey, 2003, Calverton, MD, USA: ORC Macro, 2004.

12. NSO and Macro International, National Safe Motherhood Survey, 1993, Calverton, MD, USA: Macro International, 1994, pp. 88-90; Lara D et al., Measuring induced abortion in Mexico: a comparison of four methodologies, Sociological Methods and Research, 2004, 32(4):529-558; Bongaarts J and Potter RG, Fertility, Biology and Behavior, New York: Academic Press, 1983; Rossier C, Estimating induced abortion rates: a review, Studies in Family Planning, 2003, 34(2):87-102; and Singh S, Incidence of unsafe abortion and resulting mortality and morbidity: a review of data, methods and information gaps, paper presented at the Workshop on Research on the Economic Impact of Abortion-related Mortality and Morbidity, New York, Apr. 26, 2005.

13. Singh S et al., 1997, op. cit. (see reference 4).

14. Bongaarts J and Potter R, 1983, op. cit. (see reference 12); and Harlap S, Shiono PH and Ramcharan S, A life table of spontaneous abortions and the effects of age, parity and other variables, in: Hook EB and Porter I, eds., Human Embryonic and Fetal Death, New York: Academic Press, 1980, pp. 145-158

15. Special tabulations from the 1998 Philippines Demographic and Health Survey.

16. Singh S et al., 1997, op. cit. (see reference 4).

17. Flavier JM and Chen CHC, Induced abortion in rural villages of Cavite, the Philippines: knowledge, attitudes and practice, Studies in Family Planning, 1980, 11(2):65-71.

18. Special tabulations from the 1994 Community Survey of Women in Metro Manila.

19. Singh S, Wulf D and Jones H, 1997, op. cit. (see reference 8).

20. Go MGA, Backstreet business, Newsbreak, Aug. 2003, <http://www. inq7.net/nwsbrk/2003/aug/04/nbk_5-1.htm>, accessed Mar. 8, 2004; and Mosher S, IPPF's Illegal Activities, Lifeissues.net, Dec. 2001, <http://www.lifeissues.net/writers/mos/pri_03abortionforall2. html>, accessed May 17, 2005.

21. Mosher S, 2001, op. cit. (see reference 20).

22. Pheterson G, "Medical" versus "surgical" abortion: facts, context, ideologies, <http://www.saludpromujer.org/pdf/Medicalvs. Surgical Abortion-GailPeterson.pdf>, accessed Mar. 8, 2004; Tan ML, Quiapo, Washington, Cytotec, Jul. 30, 2002, <http://www.pinoykasi. homestead.com/files/2002articles/07302002_Quiapo_Washington. htm>, accessed Mar. 8, 2004; and Conde CH, Philippines abortion crisis, International Herald Tribune, May 16, 2005, <http://www.iht.com/ articles/2005/05/15 news/phils. php>, accessed May 17, 2005.

23. Carbonell L et al., The use of misoprostol for abortion at $<9$ weeks 
gestation, European Journal of Contraception and Reproductive Health Care, 1997, 2(3): 181-185; Koopersmith TB and Mishell DR, The use of misoprostol for termination of early pregnancy, Contraception, 1996, 53(4):237-242; and Blanchard K et al., Misoprostol alone-a new method of medical abortion? Journal of the American Medical Women's Association, 55(2):189-190

24. Pheterson G, 2004, op. cit. (see reference 22).

25. Demeterio-Melgar J et al., Very intimate stories: accounts of women who have abortions, paper presented at the National Abortion Rights Meeting, Quezon City, Philippines, Apr. 26-27, 2004; Tan ML, Premarital sex (PMS) and moral panic, paper presented at the meeting Family Planning New Worlds, Baltimore, MD, USA, Dec. 10, 2002; and Personal accounts of women using cytotec/misoprostol, Sept. 18, 2000, <www sisterzeus.com/Sharing/Lyn.html>, accessed Mar. 8, 2004.

26. NSO and Macro International, 1994, op. cit. (see reference 11); and NSO and ORC Macro, 2004, op. cit. (see reference 11).

27. Raymundo CM, Xenos P and Domingo L, eds., Adolescent Sexuality in the Philippines, Quezon City, Philippines: University of the Philippines, 1999, Appendix Table 4G.

28. Special tabulations from the 1993 and 1998 Philippines Demographic and Health Surveys.

29. Singh S et al., 1997, op. cit. (see reference 4).

30. Philippine Health Social Science Association, The men in abortion (in Pilipino), paper presented at the first meeting of the Scarlet Letter Network, Quezon City, Philippines, Jan. 15, 2003; Demeterio-Melgar J et al., 2004, op. cit. (see reference 25); and David FP, Abortion experiences of selected women of reproductive age in four barangays in Bacolod City: an exploratory study, unpublished report, PAROLO Outreach \& Development Foundation, Bacolod City, Philippines, 1999.

31. Population Council, Needs and services assessed in the Philippines, Population Briefs, 2001, Vol. 7, No. 3; and Casterline JB, Perez AE and Biddlecom AE, Factors underlying unmet need in the Philippines, Studies in Family Planning, 1997, 28(3):173-191.

32. Ibid.

33. Singh S and Juarez F, 2003, op. cit. (see reference 10).

34. Shah IH, Cleland JG and Ali MM, Contraceptive use patterns and the HIV/AIDS epidemic, paper presented at the National Institutes of Health Conference on HIV and Hormonal Contraceptives, Washington, DC, Jan. 2002

35. Special tabulations from the 1993 and 1998 Demographic and Health Surveys

36. United Nations Population Fund, 5th Country Profile Updates, 2001 Report, <http://www.apdpi.org/un5/agencies/unfpa.html>, accessed Mar. 3, 2003

37. Kantner A and Westley SB, Family planning for new mothers in the Philippines, Asia-Pacific Population E Policy, No. 47, 1998.

38. Leonardo Z and Legaspi OP, Guiding principles of the Catholic bishops' conference of the Philippines on population control, <http://www cbcponline.org/documents/1990s/1990-population_control.html>, accessed Apr. 3, 2003.

39. NSO Philippines and ORC Macro, 2004, op. cit., (see reference 11).

40. Ibid.

41. EngenderHealth, Postabortion care with compassion in the Philippines, <http://www.engenderhealth.org/itf/philippines.html>, accessed Sept. 8, 2005

\section{RESUMEN}

Contexto: En las Filipinas, el aborto está legalmente restringido. No obstante, muchas mujeres procuran un aborto inducido-con frecuencia en condiciones de riesgo-para evitar los nacimientos no planeados. En 1994, la tasa estimada de abortos fue de 25 por cada 1.000 mujeres; desde entonces no se han realizado más trabajos de investigación sobre la incidencia de abortos en las Filipinas.
Métodos: Se utilizaron datos de 1.658 hospitales para calcular la incidencia de abortos en el año 2000 y evaluar las tendencias ocurridas desde 1994 a 2000, a nivel nacional y por región. Se utilizó una metodología estimativa para calcular el número total de mujeres hospitalizadas por complicaciones de abortos inducidos en 2000 (datos promedios para 1999-2001), el número total de mujeres sometidas a abortos y la tasa de abortos inducidos.

Resultados: En 2000, fueron hospitalizadas aproximadamente 78.000 mujeres para recibir atención postaborto, $469.000 \mathrm{mu-}$ jeres se habian sometido a un aborto, y la tasa de este procedimiento ascendió al 26 por 1.000, entre mujeres de 15-44 años. La tasa nacional de abortos permaneció sin cambios entre 1994 y 2000; no obstante, hubo grandes aumentos en la zona metropolitana de Manila (de 41 a 52 por 1.000 mujeres) y Visayas (de 11 a 17 por 1.000 mujeres). Los porcentajes de nacimientos no planeados y embarazos no deseados aumentaron sustancialmente en Manila, y el uso de métodos anticonceptivos tradicionales aumentó en Manila y Visayas.

Conclusión: El aumento del nivel de abortos inducidos registrado en algunas zonas puede reflejar las dificultades que tienen las mujeres en obtener anticonceptivos modernos debido a las restricciones sociales y politicas que afectan la entrega de servicios de salud. Es necesario mejorar los programas y políticas con respecto a la atención postaborto y de los servicios de anticonceptivos.

\section{RÉSUMÉ}

Contexte: Aux Philippines, l'avortement est sujet à restriction légale. Beaucoup de femmes interrompent pourtant leur grossesse-dans des conditions souvent non médicalisées-pour éviter les naissances non planifiées. En 1994, le taux d'IVG a été estimé à 25 femmes pour mille. Aucune autre recherche sur l'incidence de l'avortement n'a été menée aux Philippines.

Méthodes: Les données de 1.658 hôpitaux ont servi à estimer l'incidence de l'IVG en 2000 et à évaluer les tendances de 1994 à 2000, à l'échelle nationale et par région. Le nombre total de femmes hospitalisées pour cause de complications d'IVG en 2000 (données moyennes pour 1999-2001), le nombre total de femmes ayant recouru à l'avortement et le taux d'IVG ont été calculés par méthodologie d'estimation indirecte.

Résultats: Pour 2000, on estime à 78.000 le nombre de femmes hospitalisées pour soins après avortement, à 469.000 celui des femmes ayant subi un avortement et à 26 pour mille femmes âgées de 15 à 44 ans le taux d'IVG. À l'échelle nationale, ce taux est resté inchangé entre 1994 et 2000; d'importantes hausses ont cependant été enregistrées dans la région métropolitaine de Manille (de 41 à 52 pour mille) et aux Visayas (de 11 à 17 pour mille). Les proportions de naissances et grossesses non planifiées ont augmenté substantiellement à Manille. Le recours aux méthodes contraceptives traditionnelles est également en hausse à Manille et aux Visayas.

Conclusions: La hausse du taux d'IVG observée dans certaines régions peut être le reflet des difficultés d'obtention de contraceptifs modernes rencontrées par les femmes sous l'effet des contraintes sociales et politiques qui affectent la prestation de soins. Les politiques et programmes relatifs aux soins après avortement et aux services contraceptifs doivent être améliorés. 


\section{Acknowledgments}

The authors thank Cleopatra Alvaro, Ryan Descallar, Leo Angelo Ocampo, Gloria Oracoy and Florence Tolentino for their invaluable contribution to data collection and data processing, and Josephine Parinas for administrative assistance. Also, the authors thank the Department of Health of the Philippines for endorsing the project, and the directors and staff of the Central and Regional Hospital Licensing Units of the Department of Health for their assistance with data access. This research is supported by The David and Lucile Packard Foundation. The findings and conclusions expressed are entirely those of the authors, and do not necessarily represent the views of The David and Lucile Packard Foundation.

Author contact: ssingh@guttmacher.org 